\title{
Spiritual experiences are related to engagement of a ventral frontotemporal functional brain network: Implications for prevention and treatment of behavioral and substance addictions
}

\author{
CLAYTON H. MCCLINTOCK ${ }^{1}$, PATRICK D. WORHUNSKY ${ }^{2}$, JIANSONG XU², IRIS M. BALODIS ${ }^{2,3}$, RAJITA SINHA ${ }^{2,4,5}$, \\ LISA MILLER $^{1}$ and MARC N. POTENZA ${ }^{4,5,6,7 *}$ \\ ${ }^{1}$ Spirituality Mind Body Institute, Teachers College, Columbia University, New York, NY, USA \\ ${ }^{2}$ Department of Psychiatry, Yale University School of Medicine, New Haven, CT, USA \\ ${ }^{3}$ Peter Boris Centre for Addictions Research, Department of Psychiatry and Behavioral Neurosciences, DeGroote School of Medicine, \\ McMaster University, Hamilton, ON, Canada \\ ${ }^{4}$ Child Study Center, Yale University School of Medicine, New Haven, CT, USA \\ ${ }^{5}$ Department of Neuroscience, Yale University School of Medicine, New Haven, CT, USA \\ ${ }^{6}$ Connecticut Mental Health Center, New Haven, CT, USA \\ ${ }^{7}$ Connecticut Council on Problem Gambling, Wethersfield, CT, USA
}

(Received: August 29, 2019; revised manuscript received: October 30, 2019; accepted: December 2, 2019)

\begin{abstract}
Background and aims: Spirituality is an important component of 12-step programs for behavioral and substance addictions and has been linked to recovery processes. Understanding the neural correlates of spiritual experiences may help to promote efforts to enhance recovery processes in behavioral addictions. We recently used general linear model (GLM) analyses of functional magnetic resonance imaging data to examine neural correlates of spiritual experiences, with findings implicating cortical and subcortical brain regions. Although informative, the GLM-based approach does not provide insight into brain circuits that may underlie spiritual experiences. Methods: Spatial independent component analysis (sICA) was used to identify functional brain networks specifically linked to spiritual (vs. stressful or neutral-relaxing) conditions using a previously validated guided imagery task in 27 young adults. Results: Using sICA, engagement of a ventral frontotemporal network was identified that was engaged at the onset and conclusion of the spiritual condition in a manner distinct from engagement during the stress or neutral-relaxing conditions. Degree of engagement correlated with subjective reports of spirituality in the scanner $(r=.71, p<.001)$ and an out-of-the-magnet measure of spirituality $(r=.48, p<.018)$. Discussion and conclusion: The current findings suggest a distributed functional neural network associated with spiritual experiences and provide a foundation for investigating brain mechanisms underlying the role of spirituality in recovery from behavioral addictions.
\end{abstract}

Keywords: spirituality, independent component analysis, functional networks, ventral attention network, frontotemporal, parietal

\section{INTRODUCTION}

Spiritual experiences, characterized by a felt union with a transcendent reality larger than oneself, represent a common element across various cultures and periods of human history (Eliade, 1959; James, 1902; Newberg \& d'Aquili, 2008; Underhill, 1911). In an analysis of such experiences, James (1902) noted that they all share qualities of ineffability, transiency, passivity, and noesis. Examples range from a sense of oneness in nature to a transcendental state during communal worship, from a zone of intense physical activity to a feeling of inspiration and buoyancy during meditation or prayer. They occur during religious moments and in nonreligious contexts like during sporting competitions, musical performances, and experiencing of natural environments. While formal contemplative practices may induce such states, these experiences in which the ordinary sense of self is transcended may also occur without intention or forethought. They may range in intensity from gentle states of mindfulness to feelings of flow to deep mystical experiences (Davidson et al., 2003; Fredrickson, 2009; Maslow, 1964; Yaden, Haidt, Hood, Vago, \& Newberg, 2017).

Individuals have at times attributed deep personal meaning and significant life changes to spiritual experiences (Maslow, 1962; Waldron, 1998). Data suggest links between the regular occurrence of spiritual experiences in one's life and improved mental health and well-being that include enhanced positive affect (Greenfield, Vaillant, \& Marks, 2009; Whitehead \& Bergeman, 2011), higher quality

* Corresponding author: Marc N. Potenza, MD, PhD; Department of Neuroscience, Yale University School of Medicine, 1 Church Street, 7th floor New Haven, CT 06510, USA; Phone: +1 203737 3553; Fax: +1 203737 3591; E-mail: marc.potenza@yale.edu

This is an open-access article distributed under the terms of the Creative Commons Attribution-NonCommercial 4.0 International License, which permits unrestricted use, distribution, and reproduction in any medium for non-commercial purposes, provided the original author and source are credited, a link to the CC License is provided, and changes - if any - are indicated. 
relationships (Greenfield et al., 2009; Kalkstein \& Tower, 2009), higher levels of optimism (Ellison \& Fan, 2008), reduced risk of burnout (Holland \& Neimeyer, 2005), lower incidence of psychopathology (Greeson et al., 2011; Kalkstein \& Tower, 2009; McCauley, Tarpley, Haaz, \& Bartlett, 2008; Skarupski, Fitchett, Evans, \& Mendes de Leon, 2010), greater appreciation for the sacredness of life (Hodges, 2002; Piedmont, 1999; Vaillant, 2008), and a greater sense of meaning and purpose (Greenfield et al., 2009).

Spirituality has been linked to recovery processes in addictions. Twelve-step programs (e.g., Alcoholics Anonymous, Narcotics Anonymous, and Gamblers Anonymous) incorporate aspects of spirituality to varying degrees (Ferentzy, Skinner, \& Antze, 2010; Galanter, 2018; Galanter, Dermatis, Post, \& Sampson, 2013). Recently, we have been investigating spirituality as it relates to recovery in gambling disorders. We have found that spirituality correlates inversely with problem-gambling severity in individuals with gambling disorder at various stages of recovery (GavrielFried, Moretta, \& Potenza, 2019a). Furthermore, only spirituality and another positive psychology measures, recovery capital, remained significant in a model that also contained measures of anxiety, depression, and stressful life events in statistically predicting recovery from gambling disorder (Gavriel-Fried, Moretta, \& Potenza, 2019b). Spirituality also appears linked to recovery from gambling disorder to a greater extent in younger as compared to older adults (Gavriel-Fried, Moretta, \& Potenza, 2019c). As such, investigating spirituality has important implications for understanding recovery processes in gambling disorder, especially for younger and middle-aged adults.

Neuroimaging studies may provide valuable insight into the neural mechanisms of spiritual state experiences and their salutary effects. Previous research indicates that contemplative practices like focused awareness and open monitoring meditations are linked to structure and function of various brain regions, including the prefrontal cortex (PFC), anterior cingulate cortex (ACC), posterior cingulate cortex (PCC), insula, striatum, and amygdala, and meditative practices may promote capacities related to emotion regulation, attention control, and self-awareness (Tang, Holzel, \& Posner, 2015; Vago \& Zeidan, 2016). Yet, by design, this body of research does not specifically investigate the neural correlates of self-transcendent spiritual states.

Most studies of meditative and prayer practices utilize region-of-interest (ROI) or general linear model (GLM) analyses, which focus on brain regions. Alternate analytical approaches may identify functionally integrated activations or networks related to brain function, and these have been argued to possibly lead to more replicable findings (Bressler, 1995; Hermans, Henckens, Joëls, \& Fernández, 2014; Xu, Calhoun, \& Potenza, 2015; Xu, Calhoun, Worhunsky, et al., 2015; Xu, Potenza, \& Calhoun, 2013; $\mathrm{Xu}$ et al., 2016). One such approach is spatial independent component analysis (sICA; Calhoun, Adali, Pearlson, \& Pekar, 2001; Zhang et al., 2015). sICA is a data-driven approach that can identify brain regions that show spatial patterns of systematic activation or deactivation and may identify overlapping activations and deactivations that cancel in GLM-based analyses (Xu, Calhoun, \& Potenza, 2015;
Xu, Calhoun, Worhunsky, et al., 2015; Xu et al., 2013, 2016). sICA has been proposed to generate findings consistent with brain properties such as balanced excitation/ inhibition (Xu, Calhoun, \& Potenza, 2015; Xu, Calhoun, Worhunsky, et al., 2015; Xu et al., 2013, 2016). sICA has been applied to functional magnetic resonance imaging (fMRI) data to identify brain networks underlying specific processes like cognitive control, response inhibition, attention, and reward/loss processing (Worhunsky et al., 2013, 2016; Worhunsky, Potenza, \& Rogers, 2017; Xu, Calhoun, Pearlson, \& Potenza, 2014; Xu et al., 2013). For these reasons, we believe sICA is well suited to identify brain networks associated with spiritual experiences. Given the importance of spirituality to recovery in behavioral addictions like gambling disorder (Gavriel-Fried et al., 2019a, $2019 b, 2019 c$ ) and the relevance of understanding neural correlates of treatment outcomes to refine interventions for behavioral addictions as has been proposed theoretically (Brand, Young, Laier, Wölfling, \& Potenza, 2016, 2019; Dong \& Potenza, 2014) and demonstrated empirically in specific treatments (Zhang, Yao, Potenza, Xia, Lan, Liu, et al., 2016, Zhang, Yao, Potenza, Xia, Lan, Wang, et al., 2016), investigation of the neural correlates of spiritual experiences holds relevance for behavioral addictions.

Previously, we identified neural correlates of personalized spiritual experiences using a guided imagery task during fMRI (Miller et al., 2019). We demonstrated task validity in generating robust spiritual experiences of religious and non-religious qualities, and showed that recruitment of specific brain regions (e.g., the parietal cortex) differed in spiritual versus stressful and neutral-relaxing conditions (Miller et al., 2019). In this study, we apply sICA to the same data set to examine functional networks that may underlie spiritual as opposed to stressful or neutralrelaxing states.

Given perceptual, cognitive, and emotional aspects of spirituality, we hypothesized that networks including both cortical and subcortical areas would be implicated. Based on the GLM-based findings (Miller et al., 2019), we hypothesized that networks involving parietal function would be engaged at both the onset and ending of the conditions to a greater degree in the spiritual as compared to the stress and neutral-relaxing conditions. We further hypothesized that degree of engagement of the identified networks would correlate with subjective spiritual responses during the spiritual condition and out-of-the magnet scores on a measure of spirituality.

\section{MATERIALS AND METHODS}

\section{Participants}

The study consisted of 27 community-recruited, native English-speaking participants, as described previously (Miller et al., 2019), as well as in "Supplementary Material." Participants completed the Spirituality Scale (Delaney, 2005), a global, holistic measure of human spirituality. Study procedures were approved by the Yale Human Investigations Committee and were in accordance with the Declaration of Helsinki. Participants provided written 
informed consent and received financial compensation for completing study procedures.

\section{fMRI task, functional image acquisition, and processing}

The fMRI task, functional image acquisition, and image processing were performed as described previously (Miller et al., 2019) and detailed in the "Supplementary Material."

\section{Independent component analysis and network selection}

sICA was performed on the fMRI time series using the Group ICA of fMRI Toolbox (GIFT v1.3h; http://mialab. $\mathrm{mrn}$.org/software/gift/). An estimate of 35 maximally independent components was determined using a minimum description length criterion (Li, Adali, \& Calhoun, 2007). Data from all participants were concatenated into a single group and reduced through a principle component analysis. Neural network algorithms (Bell \& Sejnowski, 1995) were used to extract the 35 components from the group aggregate, and extraction was repeated 50 times using ICASSO to assess stability and consistency of identified components (Himberg, Hyvarinen, \& Esposito, 2004). Component time courses and spatial source maps were reconstructed and scaled to percent signal change for each session for each participant (Calhoun et al., 2001).

The spatial source maps across the six runs of each participant were averaged together, and the average spatial maps for each component were tested for significant regional loading using one-sample $t$-tests in SPM12 at a voxellevel family-wise error (FWE)-corrected $p_{\mathrm{FWE}}<.01$ and a cluster extent threshold of 100 voxels. Positive and negative clusters in functional networks represent inversely related component time courses, indicating simultaneous positive and negative engagement of different regions in the same network. That is, when a task-related $\beta$-weight is greater than zero, indicating positive network engagement, positive clusters exhibit positive signals (i.e., similar to the hemodynamic response function response) and negative clusters exhibit negative signals. By comparison, when a taskrelated $\beta$-weight is less than zero, indicating negative network engagement, positive clusters exhibit negative signals and negative clusters exhibit positive signals.

To identify components that were differentially associated with guided imagery conditions, multiple regression analyses were used to assess the task-relatedness of the component time courses. Guided imagery runs were subdivided into $20 \mathrm{~s}$ blocks of interest: the rest period immediately preceding audio (R1), the two blocks at the beginning of audio (B1 and B2), the final blocks of audio (E1 and E2), and the rest period immediately after audio (R2; Figure 1). We chose to focus on the beginning and end of the conditions based on our prior studies of emotional and motivational states (including gambling urges), given dynamic changes in brain function during these states (Potenza et al., 2003; Wexler et al., 2001). This approach also permitted examination of similar blocks across subjects, given slight variation in temporal lengths of audiotapes. Expected hemodynamic response functions were modeled for the six blocks and the single block of audio between B2 and E1 for each guided imagery run and compared to the time course of that run for each network for each participant. This process produced $\beta$-weights that represent a measure of "engagement" or "recruitment" of each network associated with each task event. The $\beta$-weights for each block from the two runs of each condition were averaged for each participant.

To identify components engaged during spirituality imagery, one-sample $t$-tests were performed on the $\beta$-weights of each block (B1, B2, E1, and E2) of the spirituality condition, identifying eight functional networks displaying significant spirituality-related engagement at a false discovery rate (FDR) corrected $p_{\mathrm{FDR}}<.05$. Two-way, four (block; B1-E2) by three (condition; spiritual, stressful, and neutral-relaxing) repeated-measures analyses of variance (ANOVAs) were then performed on $\beta$-weights to identify spirituality-related networks displaying a main effect of condition and/or a block-by-condition interaction, using Greenhouse-Geisser correction for sphericity violations. One functional network displayed a main effect of condition and a block-by-condition interaction (Bonferroni-corrected $\alpha .05 / 8=.006$ ).

\section{Additional statistical procedures}

Ratings of vividness following guided imagery conditions were tested using a repeated-measures ANOVA. Paired $t$-tests were performed on average ratings of anxiety and spirituality to compare ratings before and after guided imagery. Correlational analyses were performed to explore potential relationships between network engagement and subjective responses during the scanning sessions as well as a questionnaire assessment of spirituality on a Spirituality Scale (Delaney, 2005). Change in network engagement was computed as the difference in average $\beta$-weight during the final two blocks of each guided imagery $\left(\beta_{\mathrm{E}}\right)$ relative to the average $\beta$-weight from the first two blocks $\left(\beta_{\mathrm{B}}\right)$ of imagery. Differences in $\beta$-weights were correlated with changes in spirituality/anxiety ratings following guided imagery relative to ratings preceding imagery. The spirituality questionnaire was not completed by three participants; thus, correlations between network engagement and Spirituality Scale total scores were performed on a subset of 24 participants.

\section{Ethics}

All procedures performed in human participants were in accordance with the ethical standards of the institutional and/or national research committee and with the 1964 Helsinki Declaration and its later amendments or comparable ethical standards.

\section{RESULTS}

\section{Participants' characteristics and guided imagery ratings}

Participants included 27 young adults (12 females), between the ages of 18 and 27 years, with an average of 22.4 $(S D=2.2)$ years, and $15.1(S D=1.7)$ years of education. Two participants provided breath samples with carbonmonoxide levels consistent with regular tobacco use, and 
(a)

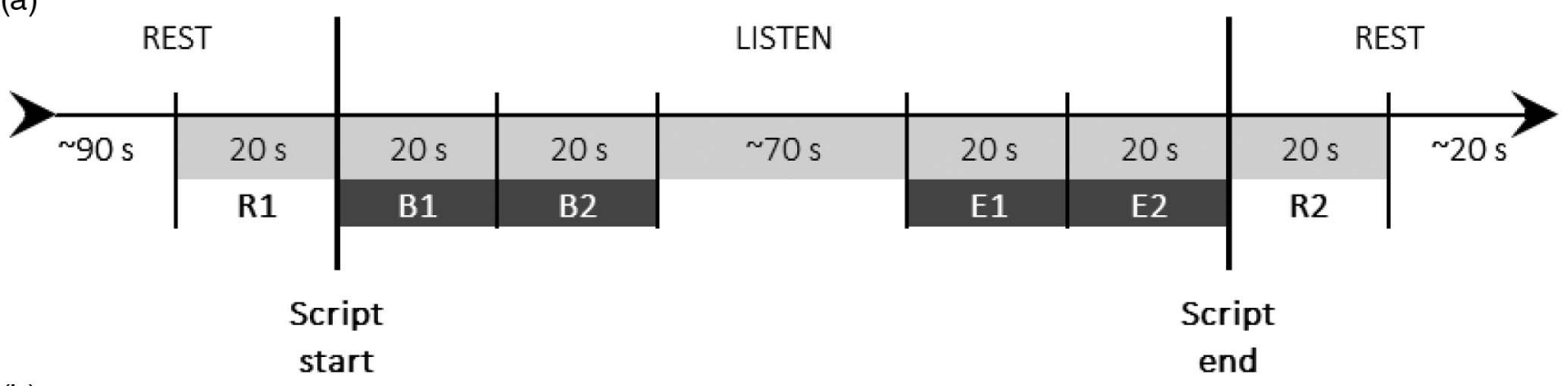

(b)
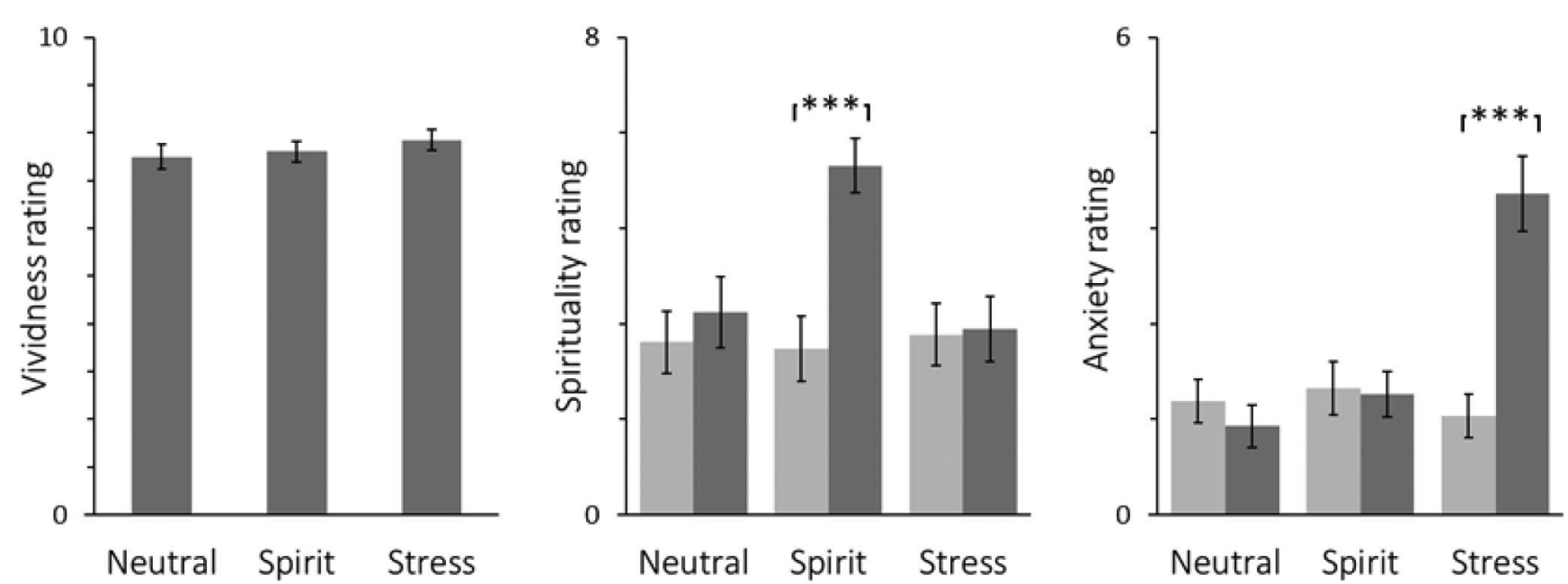

Figure 1. (a) Schematic of timeline and epochs used in fMRI data analysis. The R1 and R2 periods constitute the 20-s periods immediately prior to and immediately following the listening period when the audio file was being played and participants actively engaged in guided imagery processes. The B1 and B2 periods are the first and second 20-s periods during the beginning of the audio file listening. The E1 and E2 periods are the next-to-last and last 20-s periods at the end of the audio file listening. (b) Subjective responses on vividness of story, spiritual connection, and anxiety across the three conditions. Participants were questioned prior to listening to their individualized script ("Baseline") and following the script ("Post-imagery"). $* * * p<.001$

one participant provided a urine sample positive for cannabis use. The average score on the Spirituality Scale was $105.5(S D=20.1)$.

As reported previously (Miller et al., 2019), ratings of vividness did not differ between guided imagery conditions $\left(F_{2}, 25=1.89, \quad p=.17\right)$, spirituality imagery increased ratings of spirituality $\left(t_{26}=6.60, p<.001\right)$, and stressful imagery increased ratings of anxiety $\left(t_{26}=5.89, p<.001\right)$.

\section{Network engagement associated with spiritual experiences}

sICA identified a ventral frontotemporal network associated with spiritual imagery relative to stressful and neutral-relaxing guided imagery (Figure 2). Details regarding the regions integrated into the functional network (e.g., peak cluster locations, peak $t$ values of spatial loading, cluster sizes, and anatomical labels) are presented in Table 1. The network was composed of temporally coherent positive signals in the middle and inferior frontal cortices, superior, middle and inferior temporal cortices, insula and frontal opercula, striatum, thalamus, brainstem, and cerebellum. Concurrent negative signals in the middle and posterior cingulate and parietal cortex were also integrated into the network.

The frontotemporal network displayed a within-subjects main effect of imagery condition $\left(F_{1.4,37.4}=7.69, p=.004\right)$ and a block-by-script interaction $\left(F_{6,156}=3.59, p=.002\right)$. Pairwise tests revealed greater engagement during spiritual imagery relative to stressful $(p=.016)$ and neutral-relaxing $(p=.004)$ imagery conditions. The frontotemporal network was positively engaged during the initial block (B1) of all imagery conditions, which demonstrated positive engagement during the ending blocks of spiritual imagery (B2-E2), and was negatively engaged or not engaged during the ending blocks of stressful and neutral-relaxing imagery. Changes in network engagement at the end relative to the beginning of the spiritual imagery condition (i.e., $\beta \mathrm{E}-\beta \mathrm{B}$ ) were correlated with changes in ratings of spirituality $(r=.71, p<.001)$ following spiritual imagery and with total scores on the Spirituality Scale $(r=.48, p=.018$; Figure 3$)$.

\section{DISCUSSION}

This is the first study to examine distributed functional brain networks involved in spiritual experiences. Spiritual experiences engaged a ventral frontotemporal network that includes middle and inferior frontal cortices, superior, middle and inferior temporal cortices, frontal opercula, and anterior insula, a finding that builds upon previous neuroimaging studies of self-transcendence, religiosity, and 

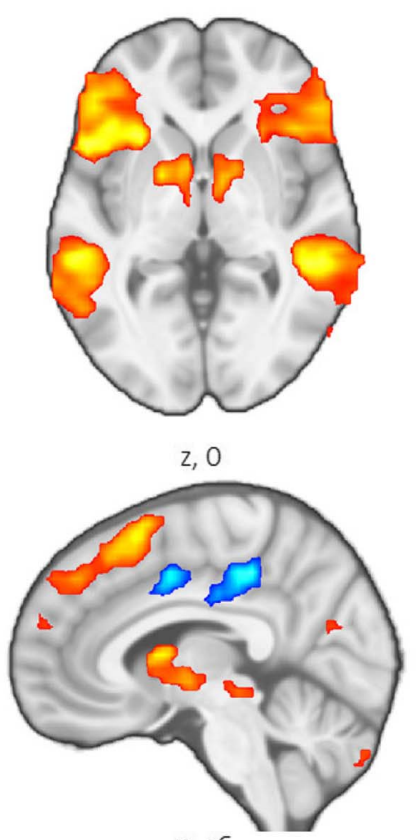

$x,+6$

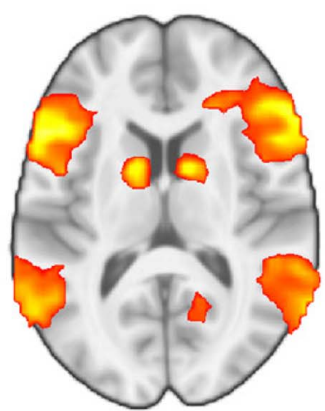

z, +12

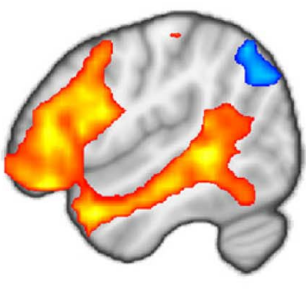

$x,+50$

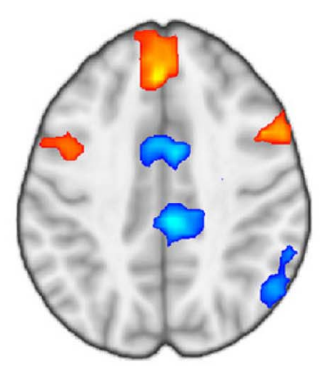

$z,+40$

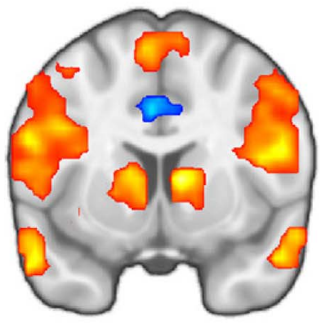

$y,+8$

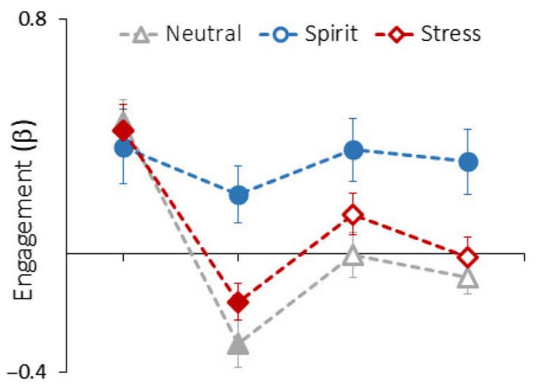

B1 B2 E1 E2

Imagery block

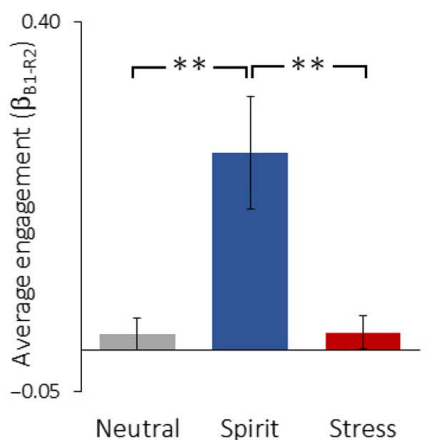

Figure 2. Engagement of a frontotemporal network during the spiritual condition. The regions comprising the frontotemporal network are shown with red-yellow color signifying regional activation during engagement and blue color indicating regional deactivation during active engagement. Plots on the right indicate engagement of the functional network by epoch and condition (top: solid markers indicate significant positive and negative engagement at $\left.p_{\mathrm{FDR}}<.05\right)$ and average engagement by condition (bottom: $* * p<.01$ )

Table 1. Regional composition of the frontotemporal network

\begin{tabular}{|c|c|c|c|c|c|c|c|}
\hline$+/-$ & Region/gyrus & BA & $k$ & $x$ & $y$ & $z$ & $t$ \\
\hline+ & $\begin{array}{l}\text { L Middle/superior/inferior temporal, middle/inferior frontal, precentral, } \\
\text { postcentral, angular, insula, and frontal operculum }\end{array}$ & $\begin{array}{c}3,6,8-10,13,19-22 \\
37-40,44-47\end{array}$ & 3,309 & -30 & 20 & -4 & 18.78 \\
\hline+ & R Caudate, pallidum, thalamus, putamen, and brainstem & & 279 & 9 & 8 & 8 & 17.71 \\
\hline+ & $\begin{array}{l}\mathrm{R} \text { Middle/superior/inferior temporal, middle/inferior frontal, precentral, } \\
\text { postcentral, angular, insula, and frontal operculum }\end{array}$ & $\begin{array}{l}3,4,6,8-10,13,18 \\
22,37-40,44-47\end{array}$ & 3,213 & 57 & -40 & -7 & 16.89 \\
\hline+ & $\mathrm{R} / \mathrm{L}$ Superior frontal and supplementary motor & $6,8,9$ & 774 & -3 & 14 & 56 & 15.73 \\
\hline+ & L Cerebellum & & 177 & -12 & -73 & -28 & 15.25 \\
\hline+ & L Caudate, pallidum, thalamus, putamen, and brainstem & & 226 & -12 & 5 & 11 & 14.38 \\
\hline+ & R Cerebellum & & 194 & 15 & -79 & -40 & 12.46 \\
\hline+ & R Middle occipital & 18,19 & 112 & 30 & -100 & 8 & 11.40 \\
\hline+ & $\mathrm{R}$ Cuneus and precuneus & 31 & 140 & 15 & -61 & 20 & 9.77 \\
\hline- & L/R Middle/posterior cingulate, and precentral & 24,31 & 291 & 6 & -34 & 44 & 15.42 \\
\hline- & $\mathrm{L} / \mathrm{R}$ Middle cingulate and supplementary motor & 24,32 & 146 & 3 & 2 & 44 & 14.08 \\
\hline- & R Angular and supramarginal & 39,40 & 136 & 48 & -55 & 47 & 12.81 \\
\hline
\end{tabular}

Note. Cluster details of the frontotemporal network at voxel-level $p_{\mathrm{FWE}}<.01, k>100 .+/-$ : positive/negative signal integration; BA: Brodmann area; $k$ : cluster size in contiguous voxels; $x, y, z$ : cluster peak location in MNI coordinates; $t$ : cluster peak $t$-score; R/L: right/left.

spirituality. An associated network included subcortical regions such as the striatum, thalamus, and brainstem. Negative signals in the middle and posterior cingulate and parietal cortices were also integrated. The degree of engagement of this network at the beginning and end distinguished the spiritual from the stressful and neutral-relaxing conditions. The degree of network engagement during the spiritual condition was associated with subjective changes in the strengths of feelings of spiritual connectedness during the spiritual condition and to an out-of-magnet measurement of spirituality more broadly. As such, our hypotheses were supported. How this network may be understood in relationship to prior findings is described below and implications for behavioral addictions and their prevention and treatment are considered below.

\section{Ventral frontotemporal network}

The observed ventral frontotemporal network appears to correspond to a well-documented ventral attention network (VAN) composed of the temporoparietal junction and ventral frontal cortex and which responds to unexpected but 
(a)

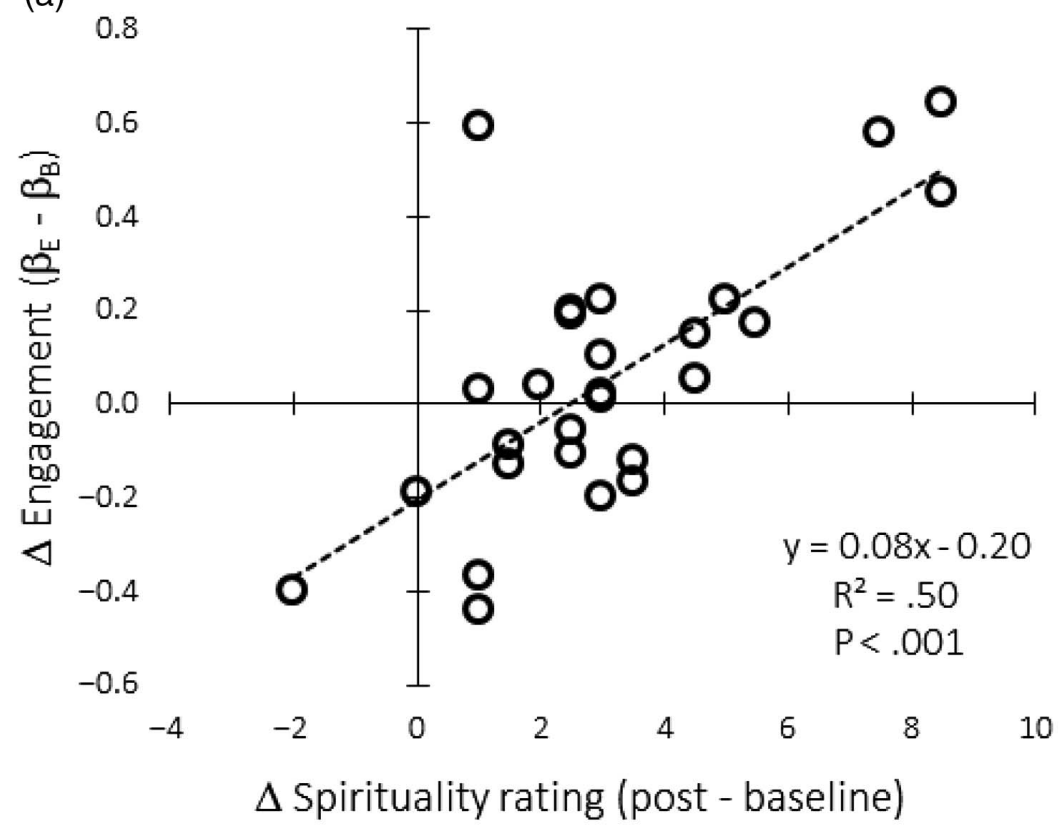

(b)

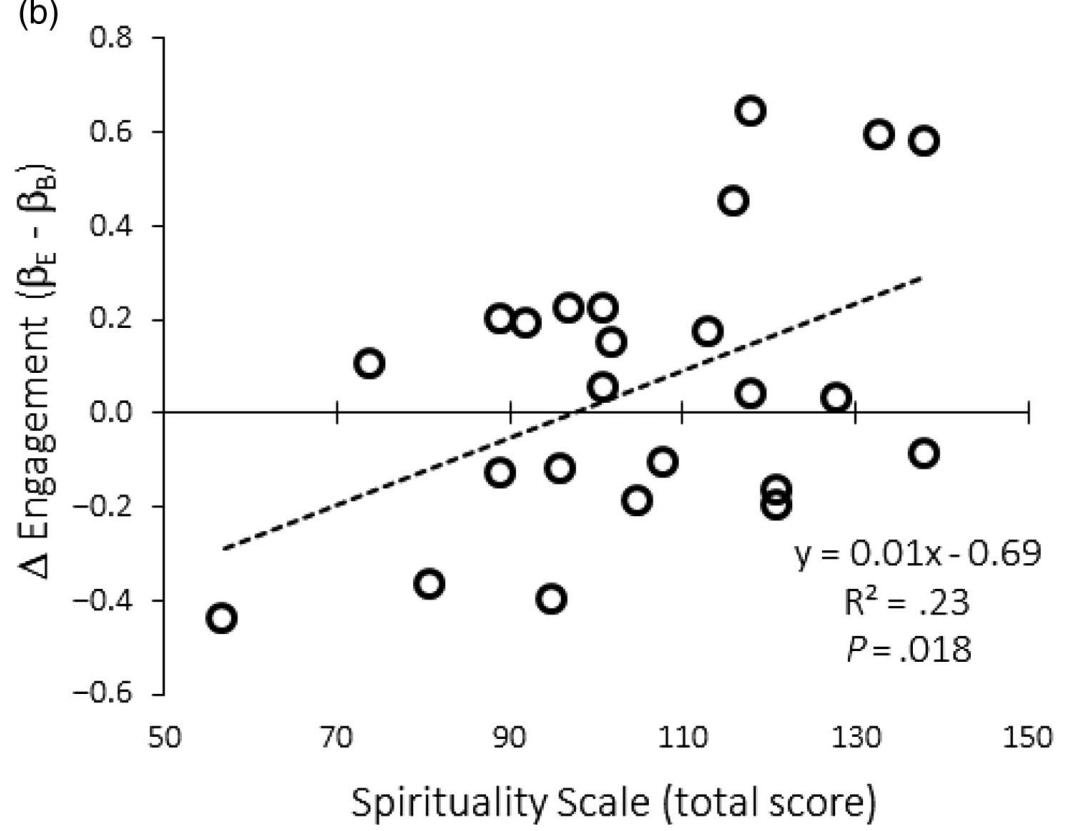

Figure 3. Correlations between changes in ventral frontotemporal network engagement and spirituality measures. Correlations are shown for changes in engagement of the ventral frontotemporal network and (a) self-reported changes in spirituality during exposure to the spirituality condition and, (b) total scores on the Spirituality Scale

behaviorally salient stimuli (Corbetta, Patel, \& Shulman, 2008; Corbetta \& Shulman, 2002; Macaluso, 2010; Vossel, Geng, \& Fink, 2014). While multiple studies report a right-hemisphere-dominant VAN, some attentional tasks including those that involve particularly rare stimuli have implicated a bilateral network (Geng \& Mangun, 2011; Serences et al., 2005; Vossel, Weidner, Thiel, \& Fink, 2009). In a task that involves responding to a visual stimulus after a predictive spatial cue is provided, a separate dorsal attention network (DAN) is implicated when the stimulus location is precued, while the VAN becomes active when stimuli appear outside the previously cued area of focus (Kincade, Abrams, Astafiev, Shulman, \& Corbetta, 2005; Vossel et al., 2009). These two primary attention networks may interact in a dynamic fashion (Vago \& Zeidan, 2016). The DAN in a top-down fashion may inhibit pathways between the VAN and incoming sensory and perceptual information, which may effectively filter out unintended information. When an unexpected but personally relevant stimulus comes into one's field of perception, this inhibitory filter may be released, giving way to VAN-mediated bottom-up, stimulus-driven, and involuntary attentional processes (Corbetta \& Shulman, 2002). That the observed pattern of engagement of the VAN, and not the DAN, is associated with the spiritual condition and not the other two conditions suggests that spiritual experiences, which James (1890) once described as "intense, voluminous, or sudden" may involve attentional processes that occur outside of 
one's voluntary control. Speculatively, this association may reflect the often unanticipated but personally meaningful nature of spiritual experiences. By extension and also speculatively, this finding suggests that neural networks underlying attentional processes may be important in the role of spirituality in recovery processes in behavioral addictions like gambling and gaming disorders. As both gambling and gaming disorders have been linked to attention-deficit hyperactivity disorder (Karaka, Canan, Saleh, \& Potenza, 2017; Potenza et al., 2019), including with respect to the disorder persistence (Bruneau et al., 2016; Fatseas et al., 2016), the findings raise the possibility that impairments in attentional processing in behavioral addictions may extent to spiritual processes and may be targeted through interventions.

In addition to involvement in attentional processes, a ventral frontotemporal network has been implicated in processing representations of others and relational bondedness. The superior temporal sulcus has been linked to social perception (Lahnakoski et al., 2012), and co-activation of frontal and temporal regions has been implicated in understanding emotions and intentions of others, including those of G-d (Kapogiannis, Barbey, Su, Krueger, \& Grafman, 2009; Lissek et al., 2008; Wang, Lee, Sigman, \& Dapretto, 2007). Activations of both frontal and temporal lobes including middle and superior temporal gyri as well as the superior frontal gyrus and anterior insula have been related to bonding with intimate others, such as mothers and romantic partners (Decety \& Jackson, 2004; Laurita, Hazan, \& Spreng, 2017; Noriuchi, Kikuchi, \& Senoo, 2008; Vanderwal, Hunyadi, Grupe, Connors, \& Schultz, 2008). Taken together, the frontotemporal network engagement in the context of the literature raises the possibility, albeit speculatively, that a feeling of relational intimacy may accompany spiritual states. This interpretation also has implications for behavioral addictions as relational attachments have been implicated in addiction processes, including with respect to the transgenerational transmission of addictions (Alvarez-Monjaras, Mayes, Potenza, \& Rutherford, 2019). As such, interventions examining spirituality in recovery from behavioral addictions should incorporate measures of social relatedness and attachment.

Previous research of large-scale neural networks have also linked frontotemporal activations to episodic memory retrieval (Barredo, Öztekin, \& Badre, 2013; Simons \& Spiers, 2003). It is therefore plausible that memories related to spiritual experiences are stronger and more salient, an interpretation consistent with the profound personal significance previously attributed to intense spiritual experiences (Maslow, 1962, 1964; Waldron, 1998). This interpretation would suggest that the enhancement of positive emotional experiences in the treatment of behavioral addictions warrants consideration. In addition, a left-hemispheric frontotemporal network has been observed to be involved in producing and comprehending spoken language (Hagoort \& Indefrey, 2014; Rodd, Longe, Randall, \& Tyler, 2010). While it is possible that language might be processed differently during spiritual states, the present data identify a bilateral frontotemporal network activation, arguably lending less support to this interpretation.
Negative signals in the PCC and inferior parietal lobule (IPL)

The negative signal in the PCC suggests a possible reduction in self-related mental processes (Brewer \& Garrison, 2014; Brewer et al., 2011; Panda et al., 2016). As a component of the default mode network and a hub with dense anatomical connections to multiple regions in the brain, the PCC has been implicated in multiple processes involving a selfreferential component. For example, the PCC is involved in activities ranging from self-evaluations to autobiographical memories to dealing with moral dilemmas involving oneself (Leech, Braga, \& Sharp, 2012; Morey et al., 2012; Sporns, 2013), and PCC deactivation has been correlated with tasks that involve focused, present-oriented attention beyond one's sense of self (Brewer, Garrison, \& WhitfieldGabrieli, 2013; Garrison et al., 2013). In behavioral and substance addictions, PCC activation has been linked to reward-related and craving processes (Kosten et al., 2006; Yao et al., 2017). For these reasons, the PCC has been proposed as a neural target for addictions, especially for meditation and mindfulness-based interventions targeting stress reduction (Brewer \& Garrison, 2014; Kral et al., 2019). As we have found that measures of spirituality relate inversely to stress-related activations in largely subcortical regions including the striatum and thalamus (McClintock et al., 2019), the findings taken together suggest important roles for both cortical and subcortical processes in the beneficial effects of spirituality as well as potential neural targets in spirituality-related interventions for addictions.

Consistent with our hypothesis, the IPL also demonstrated a concurrent negative signal. The right lateralized IPL has been implicated in body representation in three-dimensional space (Berlucchi \& Aglioti, 1997; Maguire et al., 1998; Vogeley \& Fink, 2003). This result is consistent with an expanded sense of self in space that has been reported in previous phenomenological accounts of spiritual states (Newberg \& Newberg, 2006), as well as the scripts generated for the current experiment. Reduced activity in the IPL has also been linked to a reduction in perceived distinction between self and other as well as a reduced sense of agency (Uddin, Molnar-Szakacs, Zaidel, \& Iacoboni, 2006). Thus, these regional deactivations are consistent with the notion that perceptual changes occur. More specifically, identification with one's physical self-sense may become more relaxed while, simultaneously, perceived boundaries between self and other may become more diffuse. Taken together, these changes may give rise to a less bounded and more expanded sense of self. Supporting this interpretation, reductions in activity in the inferior parietal cortex (and PCC) have been associated with self-transcendence, religious and spiritual beliefs, and religious and spiritual commitments (Brewer et al., 2011; Crescentini, Aglioti, Fabbro, \& Urgesi, 2014; Urgesi, Aglioti, Skrap, \& Fabbro, 2010).

\section{Subcortical involvement}

The identified frontotemporal network also contained concurrent positive signals in subcortical regions that include the putamen and caudate nucleus, illuminating possible neural substrates of the concomitant emotional quality associated 
with spiritual states. These regions have been implicated in the processing of positive and rewarding emotions like love and bliss, which often accompany spiritual experiences (Bartels \& Zeki, 2000; Beauregard \& Paquette, 2006; Damasio et al., 2000; Langeslag, van der Veen, \& Röder, 2014). Because the neutral-relaxing condition also consisted of positively valenced experiences (e.g., listening to pleasant music or relaxing with family members), the relative involvement of these regions suggests that the positive emotion associated with spiritual experience is distinct from and may be more pronounced than simply recalling a positive memory. Saver and Rabin (1997) previously proposed that subcortical limbic regions are responsible for salient aspects of spiritual experiences including a sense of unity and feelings of ecstasy. That dorsal striatal and not ventral striatal regions were implicated in this study suggests that people may seek these experiences not because of an anticipated reward but rather from an intrinsically motivated state, possibly reinforced through previous positive experiences (Balleine, Delgado, \& Hikosaka, 2007; Delgado, 2007). Given the role of the dorsal striatum in other processes (e.g., habits) and overlap with regions of the striatum implicated in reward processing, alternate interpretations exist and warrant direct examination in future studies (Brewer \& Potenza, 2008; Everitt \& Robbins, 2005; Yin \& Knowlton, 2006). Thus, while spiritual states may represent a form of positive reinforcement that may increase a person's likelihood of continuing to seek more (Otto, 1946; Underhill, 1911), given the wide range of processes in which the striatum participates, this and other possibilities should be studied directly in future experiments.

\section{Spiritual experiences and volitional contemplative practices}

Reduced PCC and IPL activity represents a common feature across a variety of meditative practices and spiritual experiences (Brewer et al., 2011; Fox et al., 2016; Urgesi et al., 2010), reflective of reduced conceptual, and self-related processing. Dorsal striatal activity, however, is not typically implicated in volitional contemplative practices (Farb et al., 2007; Fox et al., 2016; Garrison, Zeffiro, Scheinost, Constable, \& Brewer, 2015), potentially reflecting an absence of concomitant positive emotion, although some exceptions do exist with certain practices (Hagerty et al., 2013; Tang et al., 2009). Furthermore, in contrast to our findings on spiritual states, volitional practices like focused attention and open-monitoring meditations activate neural regions involved in enhancing attentional control, particularly the ACC (Allen et al., 2012; Hölzel et al., 2007; Tang, Tang, \& Posner, 2016). The ACC monitors multiple channels of information and enables voluntary executive control of attention (Van Veen \& Carter, 2002). Other areas related to executive attention like the dorsolateral and ventrolateral prefrontal cortices have also been implicated in meditative practices (Allen et al., 2012; Hölzel et al., 2013). However, in a spiritual state, by contrast, there appear to be fewer correlates of volitional attention.

\section{Implications for the prevention and treatment of addictions}

Mindfulness-based practices often include spiritual elements and have empirical support in the treatment of addictions
(Brewer, Bowen, Smith, Marlatt, \& Potenza, 2010; Brewer et al., 2009; Witkiewitz et al., 2014). Similarly, mindfulness has been considered in the treatment of gambling disorder (Chen, Jindani, Perry, \& Turner, 2014; de Lisle, Dowling, \& Allen, 2012; Shonin, Van Gordon, \& Griffiths, 2014), Internet gaming disorder (Zhang, Yao, Potenza, Xia, Lan, Liu, et al., 2016a; Zhang, Yao, Potenza, Xia, Lan, Wang, et al., 2016), and compulsive sexual behaviors (Blycker \& Potenza, 2018). As such, the current findings suggests mechanisms by which aspects of such interventions may operate, and studies directly examining how interventions that include mindfulness-related elements should consider examining directly changes in spiritual processes and frontotemporal-network function. Such work could be extended to understanding how 12-step programs promote recovery (Ferentzy et al., 2010; Galanter, 2018; Galanter et al., 2013) and how mindfulness-based practice may promote health (Lin et al., 2019). As spirituality may mitigate against stress-related illnesses (Koenig, 2012) and stress has been linked to drug and behavioral addictions (Potenza et al., 2019; Sinha, 2008), including at neural levels (Potenza et al., 2012), direct examination of how spirituality may prevent substance and behavioral addictions and operate through the reduction of stress should be conducted. Preliminary data in this area suggest that spirituality may buffer against neural responses to stress, particularly at subcortical levels (McClintock et al., 2019). However, the current findings suggest that spirituality may also promote positive health psychological benefits that operate through VAN-related neural processes. The extent to which such networks may also influence other positive health psychology domains (such as those operationalized as component of recovery capital; Gavriel-Fried et al., 2019a, 2019b, 2019c) and promote resiliency against and recovery from behavioral addictions warrants direct examination in future studies.

\section{Limitations, future directions, and conclusions}

Limitations should be noted. Although participants represented a variety of religious backgrounds, the study drew from a moderately small sample of young adults, which may limit the ability to detect more subtle between-condition differences and increase the possibility of false-positive findings. However, the sample size is standard for withinsubject designs, and the current findings survived clusterlevel corrections, although these findings warrant replication before drawing definitive conclusions. Further investigations that employ larger samples representing a range of cultures and age groups would also allow for broader generalization and for analyses of specific categories of spiritual experiences. Because the neutral-relaxing condition also consisted of positively valenced experiences (e.g., listening to pleasant music or relaxing with family members), the relative involvement of these regions suggests that the positive emotion associated with spiritual experience is distinct from and may be more pronounced than simply recalling a positive memory (e.g., communal worship experiences vs. connections with nature). Due to the relatively sparse literature on both spiritual experience and ventral frontotemporal networks, reverse inferences that were discussed should be considered cautiously. 
Despite limitations, the current findings suggest a pattern of neural networks associated with spiritual experiences and have potentially important implications for understanding recovery from behavioral addictions. Correlated with both perceived subjective changes in spirituality and overall spirituality, the identified functional network is spatially consistent with networks implicated in a range of processes, chiefly: (a) involuntary reorientation of attention, (b) a more interconnected perception of oneself, and (c) enhanced positive affect consistent with attachment or bonding. Given that spirituality has been linked to better mental health across contexts and conditions, future studies should examine the extent to which the findings may relate to improved mental health, especially within clinical settings relating to behavioral addictions.

Funding sources: This work was supported in part by the National Institutes of Health (R01DA039136), the Connecticut State Department of Mental Health and Addiction Services, the Connecticut Mental Health Center, the Connecticut Council on Problem Gambling, a Center of Excellence in Gambling Research Award from the National Center for Responsible Gaming, and the Peter Boris Centre for Addictions Research.

Authors' contribution: LM and MNP conceived original study idea. RS designed guided imagery paradigm and LM, MNP, RS, CHMC, and IMB contributed to study design. IMB and RS coordinated data collection. JX preprocessed data and performed ICA. CHMC and PDW interpreted results and wrote the manuscript. All authors revised the manuscript critically and approved the final version. CHMC, PDW, LM, and MNP contributed equally to the generation of the manuscript.

Conflict of interest: None of the authors have any relevant financial disclosures. Dr. MNP has received financial support or compensation for the following: he has consulted for RiverMend Health, Game Day Data, the Addiction Policy Forum, and Opiant Pharmaceuticals; has received research support from Mohegan Sun Casino and the National Center for Responsible Gaming; and has consulted for gambling and legal entities on issues related to addictive disorders.

\section{REFERENCES}

Allen, M., Dietz, M., Blair, K. S., van Beek, M., Rees, G., Vestergaard-Poulsen, P., Lutz, A., \& Roepstorff, A. (2012). Cognitive-affective neural plasticity following active-controlled mindfulness intervention. Journal of Neuroscience, 32(44), 15601-15610. doi:10.1523/JNEUROSCI.2957-12.2012

Alvarez-Monjaras, M., Mayes, L. C., Potenza, M. N., \& Rutherford, H. J. V. (2019). A developmental model of addictions: Integrating neurobiological and psychodynamic theories through the lens of attachment. Attachment and Human Development, 21(6), 616-637. doi:10.1080/14616734.2018.1498113

Balleine, B. W., Delgado, M. R., \& Hikosaka, O. (2007). The role of the dorsal striatum in reward and decision-making. Journal of
Neuroscience, 27(31), 8161-8165. doi:10.1523/JNEUROSCI. 1554-07.2007

Barredo, J., Öztekin, I., \& Badre, D. (2013). Ventral frontotemporal pathway supporting cognitive control of episodic memory retrieval. Cerebral Cortex, 25(4), 1004-1019. doi:10.1093/cercor/bht291

Bartels, A., \& Zeki, S. (2000). The neural basis of romantic love. Neuroreport, 11(17), 3829-3834. doi:10.1097/00001756200011270-00046

Beauregard, M., \& Paquette, V. (2006). Neural correlates of a mystical experience in Carmelite nuns. Neuroscience Letters, 405(3), 186-190. doi:10.1016/j.neulet.2006.06.060

Bell, A. J., \& Sejnowski, T. J. (1995). An information-maximization approach to blind separation and blind deconvolution. Neural Computation, 7(6), 1129-1159. doi:10.1162/neco. 1995.7.6.1129

Berlucchi, G., \& Aglioti, S. (1997). The body in the brain: Neural bases of corporeal awareness. Trends in Neurosciences, 20(12), 560-564. doi:10.1016/S0166-2236(97)01136-3

Blycker, G. R., \& Potenza, M. N. (2018). A mindful model of sexual health: A review and implications of the model for the treatment of individuals with compulsive sexual behavior disorder. Journal of Behavioral Addictions, 7(4), 917-929. doi:10.1556/2006.7.2018.127

Brand, M., Wegmann, E., Stark, R., Müller, A., Wölfling, K., Robbins, T. W., \& Potenza, M. N. (2019). The Interaction of Person-Affect-Cognition-Execution (I-PACE) model for addictive behaviors: Update, generalization to addictive behaviors beyond Internet-use disorders, and specification of the process character of addictive behaviors. Neuroscience and Biobehavioral Reviews, 104, 1-10. doi:10.1016/j.neubiorev. 2019.06.032

Brand, M., Young, K., Laier, C., Wölfling, K., \& Potenza, M. N. (2016). Integrating psychological and neurobiological considerations regarding the development and maintenance of specific Internet-use disorders: An Interaction of PersonAffect-Cognition-Execution (I-PACE) model. Neuroscience and Biobehavioral Reviews, 71, 252-266. doi:10.1016/ j.neubiorev.2016.08.033

Bressler, S. L. (1995). Large-scale cortical networks and cognition. Brain Research Reviews, 20(3), 288-304. doi:10.1016/01650173(94)00016-I

Brewer, J. A., Bowen, S., Smith, J. T., Marlatt, G. A., \& Potenza, M. N. (2010). Mindfulness-based treatments for co-occurring depression and substance use disorders: What can we learn from the brain? Addiction, 105(10), 1698-1706. doi:10.1111/ j.1360-0443.2009.02890.x

Brewer, J. A., \& Garrison, K. A. (2014). The posterior cingulate cortex as a plausible mechanistic target of meditation: Findings from neuroimaging. Annals of the New York Academy of Sciences, 1307(1), 19-27.

Brewer, J. A., Garrison, K. A., \& Whitfield-Gabrieli, S. (2013). What about the "Self" is processed in the posterior cingulate cortex? Frontiers in Human Neuroscience, 7, 647. doi:10.3389/fnhum.2013.00647

Brewer, J. A., \& Potenza, M. N. (2008). The neurobiology and genetics of impulse control disorders: Relationships to drug addictions. Biochemical Pharmacology, 75(1), 63-75. doi:10.1016/j.bcp.2007.06.043

Brewer, J. A., Sinha, R., Chen, J. A., Michalsen, R. N., Babuscio, T. A., Nich, C., Grier, A., Bergquist, K. L., Reis, D. L., 
Potenza, M. N., Carroll, K. M., \& Potenza, M. N. (2009). Mindfulness training and stress reactivity in substance abuse: Results from a randomized, controlled stage I pilot study. Substance Abuse, 30(4), 306-317. doi:10.1080/ 08897070903250241

Brewer, J. A., Worhunsky, P. D., Gray, J. R., Tang, Y. Y., Weber, J., \& Kober, H. (2011). Meditation experience is associated with differences in default mode network activity and connectivity. Proceedings of the National Academy of Sciences of the United States of America, 108(50), 20254-20259. doi:10.1073/ pnas. 1112029108

Bruneau, M., Grall-Bronnec, M., Vénisse, J. L., Romo, L., Valleur, M., Magalon, D., Fatséas, M., Chéreau-Boudet, I., Luquiens, A., JEU-Group, Challet-Bouju, G., \& Hardouin, J. B. (2016). Gambling transitions among adult gamblers: A multi-state model using a Markovian approach applied to the JEU cohort. Addictive Behaviors, 57, 13-20. doi:10.1016/j.addbeh.2016. 01.010

Calhoun, V., Adali, T., Pearlson, G., \& Pekar, J. (2001). A method for making group inferences from functional MRI data using independent component analysis. Human Brain Mapping, 14(3), 140-151. doi:10.1002/hbm.1048

Chen, P., Jindani, F., Perry, J., \& Turner, N. L. (2014). Mindfulness and problem gambling treatment. Asian Journal of Gambling Issues and Public Health, 4(1), 2. doi:10.1186/ 2195-3007-4-2

Corbetta, M., Patel, G., \& Shulman, G. L. (2008). The reorienting system of the human brain: From environment to theory of mind. Neuron, 58(3), 306-324. doi:10.1016/j.neuron.2008. 04.017

Corbetta, M., \& Shulman, G. L. (2002). Control of goal-directed and stimulus-driven attention in the brain. Nature Reviews: Neuroscience, 3(3), 201-215. doi:10.1038/nrn755

Crescentini, C., Aglioti, S. M., Fabbro, F., \& Urgesi, C. (2014). Virtual lesions of the inferior parietal cortex induce fast changes of implicit religiousness/spirituality. Cortex, 54, 1-15. doi:10.1016/j.cortex.2014.01.023

Damasio, A. R., Grabowski, T. J., Bechara, A., Damasio, H., Ponto, L. L., Parvizi, J., \& Hichwa, R. D. (2000). Subcortical and cortical brain activity during the feeling of self-generated emotions. Nature Neuroscience, 3(10), 1049-1056. doi:10. 1038/79871

Davidson, R. J., Kabat-Zinn, J., Schumacher, J., Rosenkranz, M., Muller, D., Santorelli, S. F., Urbanowski, F., Harrington, A., Bonus, K., \& Sheridan, J. F. (2003). Alterations in brain and immune function produced by mindfulness meditation. Psychosomatic Medicine, 65(4), 564-570. doi:10.1097/ 01.PSY.0000077505.67574.E3

de Lisle, S. M., Dowling, N. A., \& Allen, J. S. (2012). Mindfulness and problem gambling: A review of the literature. Journal of Gambling Studies, 28(4), 719-739. doi:10.1007/s10899-0119284-7

Decety, J., \& Jackson, P. L. (2004). The functional architecture of human empathy. Behavioral and Cognitive Neuroscience Reviews, 3(2), 71-100. doi:10.1177/1534582304267187

Delaney, C. (2005). The Spirituality Scale: Development and psychometric testing of a holistic instrument to assess the human spiritual dimension. Journal of Holistic Nursing, 23(2), 145-167; discussion 168-171. doi:10.1177/089801010 5276180
Delgado, M. R. (2007). Reward-related responses in the human striatum. Annals of the New York Academy of Sciences, 1104(1), 70-88. doi:10.1196/annals.1390.002

Dong, G., \& Potenza, M. N. (2014). A cognitive-behavioral model of Internet gaming disorder: Theoretical underpinnings and clinical implications. Journal of Psychiatric Research, 58, 7-11. doi:10.1016/j.jpsychires.2014.07.005

Eliade, M. (1959). The sacred and the profane; the nature of religion (1st American ed.). New York, NY: Harcourt.

Ellison, C. G., \& Fan, D. (2008). Daily spiritual experiences and psychological well-being among US adults. Social Indicators Research, 88(2), 247-271. doi:10.1007/s11205-007-9187-2

Everitt, B. J., \& Robbins, T. W. (2005). Neural systems of reinforcement for drug addiction: From actions to habits to compulsion. Nature Neuroscience, 8(11), 1481-1489. doi:10. 1038/nn1579

Farb, N. A., Segal, Z. V., Mayberg, H., Bean, J., McKeon, D., Fatima, Z., \& Anderson, A. K. (2007). Attending to the present: Mindfulness meditation reveals distinct neural modes of self-reference. Social Cognitive and Affective Neuroscience, 2(4), 313-322. doi:10.1093/scan/nsm030

Fatseas, M., Alexandre, J. M., Venisse, J. L., Romo, L., Valleur, M., Magalon, D., Chereau-Boudet, I., Luquiens, A., Guilleux, A., Groupe, J., Challet-Bouju, G., \& Grall-Bronnec, M. (2016). Gambling behaviors and psychopathology related to attentiondeficit/hyperactivity disorder (ADHD) in problem and nonproblem adult gamblers. Psychiatry Research, 239, 232-238. doi:10.1016/j.psychres.2016.03.028

Ferentzy, P., Skinner, W., \& Antze, P. (2010). The serenity prayer: Secularism and spirituality in Gamblers Anonymous. Journal of Groups in Addiction \& Recovery, 5(2), 124-144. doi:10. 1080/15560351003766125

Fox, K. C., Dixon, M. L., Nijeboer, S., Girn, M., Floman, J. L., Lifshitz, M., Ellamil, M., Sedlmeier, P., \& Christoff, K. (2016). Functional neuroanatomy of meditation: A review and metaanalysis of 78 functional neuroimaging investigations. Neuroscience and Biobehavioral Reviews, 65, 208-228. doi:10.1016/ j.neubiorev.2016.03.021

Fredrickson, B. (2009). Positivity. New York, NY: Harmony.

Galanter, M. (2018). Combining medically assisted treatment and twelve-step programming: A perspective and review. The American Journal of Drug and Alcohol Abuse, 44(2), 151-159. doi:10.1080/00952990.2017.1306747

Galanter, M., Dermatis, H., Post, S., \& Sampson, C. (2013). Spirituality-based recovery from drug addiction in the twelve-s tep fellowship of narcotics anonymous. Journal of Addiction Medicine, 7(3), 189-195. doi:10.1097/ADM.0b013e31828a 0265

Garrison, K. A., Scheinost, D., Worhunsky, P. D., Elwafi, H. M., Thornhill, T. A., Thompson, E., Saron, C., Desbordes, G., Kober, H., Hampson, M., Gray, J. R., Constable, R. T., Papademetris, X., \& Brewer, J. A. (2013). Real-time fMRI links subjective experience with brain activity during focused attention. Neuroimage, 81, 110-118. doi:10.1016/ j.neuroimage.2013.05.030

Garrison, K. A., Zeffiro, T. A., Scheinost, D., Constable, R. T., \& Brewer, J. A. (2015). Meditation leads to reduced default mode network activity beyond an active task. Cognitive, Affective \& Behavioral Neuroscience, 15(3), 712-720. doi:10.3758/ s13415-015-0358-3 
Gavriel-Fried, B., Moretta, T., \& Potenza, M. N. (2019a). Modeling intrinsic spirituality in gambling disorder. Addiction Research \& Theory. Advance online publication. 1-7. doi:10.1080/16066359.2019.1622002

Gavriel-Fried, B., Moretta, T., \& Potenza, M. N. (2019b). Associations between recovery capital, spirituality and DSM-5 symptom improvement in gambling disorder. Psychology of Addictive Behaviors. Advance online publication. doi:10.1037/ adb0000492

Gavriel-Fried, B., Moretta, T., \& Potenza, M. N. (2019c). Recovery capital and symptom improvement in gambling disorder: Correlations with spirituality and stressful life events in younger but not older adults. Journal of Gambling Studies. Advance online publication. 1-12. doi:10.1007/s10899-019-09905-5

Geng, J. J., \& Mangun, G. R. (2011). Right temporoparietal junction activation by a salient contextual cue facilitates target discrimination. Neuroimage, 54(1), 594-601. doi:10.1016/ j.neuroimage.2010.08.025

Greenfield, E. A., Vaillant, G. E., \& Marks, N. F. (2009). Do formal religious participation and spiritual perceptions have independent linkages with diverse dimensions of psychological well-being? Journal of Health and Social Behavior, 50(2), 196-212. doi:10.1177/002214650905000206

Greeson, J. M., Webber, D. M., Smoski, M. J., Brantley, J. G., Ekblad, A. G., Suarez, E. C., \& Wolever, R. Q. (2011). Changes in spirituality partly explain health-related quality of life outcomes after Mindfulness-Based Stress Reduction. Journal of Behavioral Medicine, 34(6), 508-518. doi:10.1007/ s10865-011-9332-x

Hagerty, M. R., Isaacs, J., Brasington, L., Shupe, L., Fetz, E. E., \& Cramer, S. C. (2013). Case study of ecstatic meditation: fMRI and EEG evidence of self-stimulating a reward system. Neural Plasticity, 2013, 1-12. doi:10.1155/2013/653572

Hagoort, P., \& Indefrey, P. (2014). The neurobiology of language beyond single words. Annual Review of Neuroscience, 37(1), 347-362. doi:10.1146/annurev-neuro-071013-013847

Hermans, E. J., Henckens, M. J., Joëls, M., \& Fernández, G. (2014). Dynamic adaptation of large-scale brain networks in response to acute stressors. Trends in Neurosciences, 37(6), 304-314. doi:10.1016/j.tins.2014.03.006

Himberg, J., Hyvärinen, A., \& Esposito, F. (2004). Validating the independent components of neuroimaging time series via clustering and visualization. Neuroimage, 22(3), 1214-1222. doi:10.1016/j.neuroimage.2004.03.027

Hodges, S. (2002). Mental health, depression, and dimensions of spirituality and religion. Journal of Adult Development, 9(2), 109-115. doi:10.1023/A:1015733329006

Holland, J. M., \& Neimeyer, R. A. (2005). Reducing the risk of burnout in end-of-life care settings: The role of daily spiritual experiences and training. Palliat Support Care, 3(3), 173-181. doi:10.1017/S1478951505050297

Hölzel, B. K., Hoge, E. A., Greve, D. N., Gard, T., Creswell, J. D., Brown, K. W., Barrett, L. F., Schwartz, C., Vaitl, D., \& Lazar, S. W. (2013). Neural mechanisms of symptom improvements in generalized anxiety disorder following mindfulness training. NeuroImage: Clinical, 2, 448-458. doi:10.1016/j.nicl.2013. 03.011

Hölzel, B. K., Ott, U., Hempel, H., Hackl, A., Wolf, K., Stark, R., $\&$ Vaitl, D. (2007). Differential engagement of anterior cingulate and adjacent medial frontal cortex in adept meditators and non-meditators. Neuroscience Letters, 421(1), 16-21. doi:10. 1016/j.neulet.2007.04.074

James, W. (1890). The principles of psychology (Vol. 1). New York, NY: Henry Holt and Company.

James, W. (1902). The varieties of religious experience: A study in human nature. New York, NY: Longmans, Green, and co.

Kalkstein, S., \& Tower, R. B. (2009). The daily spiritual experiences scale and well-being: Demographic comparisons and scale validation with older Jewish adults and a diverse internet sample. Journal of Religion and Health, 48(4), 402-417. doi:10.1007/s10943-008-9203-0

Kapogiannis, D., Barbey, A. K., Su, M., Krueger, F., \& Grafman, J. (2009). Neuroanatomical variability of religiosity. PLoS One, 4(9), e 7180. doi:10.1371/journal.pone.0007180

Karaka, S., Canan, F., Saleh, A., \& Potenza, M. N. (2017). Comorbidity between behavioral addictions and attention deficit/hyperactivity disorder: A systematic review. International Journal of Mental Health and Addiction, 15(3), 701-724. doi:10.1007/s11469-016-9660-8

Kincade, J. M., Abrams, R. A., Astafiev, S. V., Shulman, G. L., \& Corbetta, M. (2005). An event-related functional magnetic resonance imaging study of voluntary and stimulus-driven orienting of attention. Journal of Neuroscience, 25(18), 4593-4604. doi:10.1523/JNEUROSCI.0236-05.2005

Koenig, H. G. (2012). Religion, spirituality, and health: The research and clinical implications. ISRN Psychiatry, 2012, 1-33. doi: $10.5402 / 2012 / 278730$

Kosten, T. R., Scanley, B. E., Tucker, K. A., Oliveto, A., Prince, C., Sinha, R., Potenza, M. N., Skudlarski, P., \& Wexler, B. E. (2006). Cue-induced brain activity changes and relapse in cocaine dependent patients. Neuropsychopharmacology, 31(3), 644-650. doi:10.1038/sj.npp.1300851

Kral, T. R. A., Imhoff-Smith, T., Dean, D. C., Grupe, D., Adluru, N., Patsenko, E., Mumford, J. A., Goldman, R., Rosenkranz, M. A., \& Davidson, R. J. (2019). Mindfulness-based stress reduction-related changes in posterior cingulate resting brain connectivity. Social Cognitive and Affective Neuroscience, 14(7), 777-787. doi:10.1093/scan/nsz050

Lahnakoski, J. M., Glerean, E., Salmi, J., Jaaskelainen, I. P., Sams, M., Hari, R., \& Nummenmaa, L. (2012). Naturalistic FMRI mapping reveals superior temporal sulcus as the hub for the distributed brain network for social perception. Frontiers in Human Neuroscience, 6, 233. doi:10.3389/fnhum.2012.00233

Langeslag, S. J., van der Veen, F. M., \& Röder, C. H. (2014). Attention modulates the dorsal striatum response to love stimuli. Human Brain Mapping, 35(2), 503-512. doi:10.1002/ hbm. 22197

Laurita, A. C., Hazan, C., \& Spreng, R. N. (2017). Dissociable patterns of brain activity for mentalizing about known others: A role for attachment. Social Cognitive and Affective Neuroscience, 12(7), 1072-1082. doi:10.1093/scan/nsx040

Leech, R., Braga, R., \& Sharp, D. J. (2012). Echoes of the brain within the posterior cingulate cortex. Journal of Neuroscience, 32(1), 215-222. doi:10.1523/JNEUROSCI.3689-11.2012

Li, Y. O., Adali, T., \& Calhoun, V. D. (2007). Estimating the number of independent components for functional magnetic resonance imaging data. Human Brain Mapping, 28(11), 1251-1266. doi:10.1002/hbm.20359

Lin, C. Y., Potenza, M. N., Broström, A., Blycker, G. R., Ulander, M., \& Pakpour, A. H. (2019). Mindfulness-Based Cognitive 
Therapy for Sexuality (MBCT-S) improves sexual functioning and intimacy among older women with epilepsy: A multicenter randomized controlled trial. Seizure, 73, 64-74. doi:10.1016/ j.seizure.2019.10.010

Lissek, S., Peters, S., Fuchs, N., Witthaus, H., Nicolas, V., Tegenthoff, M., Juckle, G., \& Brune, M. (2008). Cooperation and deception recruit different subsets of the theory-of-mind network. PLoS One, 3(4), e2023. doi:10.1371/journal.pone. 0002023

Macaluso, E. (2010). Orienting of spatial attention and the interplay between the senses. Cortex, 46(3), 282-297. doi:10.1016/ j.cortex.2009.05.010

Maguire, E. A., Burgess, N., Donnett, J. G., Frackowiak, R. S., Frith, C. D., \& O'keefe, J. (1998). Knowing where and getting there: A human navigation network. Science, 280(5365), 921-924. doi:10.1126/science.280.5365.921

Maslow, A. H. (1962). Lessons from the peak-experiences. Journal of Humanistic Psychology, 2(1), 9-18. doi:10.1177/ 002216786200200102

Maslow, A. H. (1964). Religions, values, and peak-experiences (Vol. 35). Columbus, OH: Ohio State University Press.

McCauley, J., Tarpley, M. J., Haaz, S., \& Bartlett, S. J. (2008). Daily spiritual experiences of older adults with and without arthritis and the relationship to health outcomes. Arthritis and Rheumatism, 59(1), 122-128. doi:10.1002/art.23246

McClintock, C. H., Worhunsky, P. D., Balodis, I. M., Sinha, R., Miller, L., \& Potenza, M. N. (2019). How spirituality may mitigate against stress and related mental disorders: A review and preliminary neurobiological evidence. Current Behavioral Neuroscience Reports. Advance online publication. 1-10. doi:10.1007/s40473-019-00195-0

Miller, L., Balodis, I. M., McClintock, C. H., Xu, J., Lacadie, C. M., Sinha, R., \& Potenza, M. N. (2019). Neural correlates of personalized spiritual experiences. Cerebral Cortex, 29(6), 2331-2338. doi:10.1093/cercor/bhy102

Morey, R. A., McCarthy, G., Selgrade, E. S., Seth, S., Nasser, J. D., \& LaBar, K. S. (2012). Neural systems for guilt from actions affecting self versus others. Neuroimage, 60(1), 683-692. doi:10.1016/j.neuroimage.2011.12.069

Newberg, A., \& d'Aquili, E. G. (2008). Why God won't go away: Brain science and the biology of belief. New York, NY: Ballantine Books.

Newberg, A. B., \& Newberg, S. K. (2006). A neuropsychological perspective on spiritual development. In E. C. Roehlkepartain, P. E. King, L. Wagener, \& P. L. Benson (Eds.), The handbook of spiritual development in childhood and adolescence (pp. 183-196). Thousand Oaks, CA: Sage Publications, Inc.

Noriuchi, M., Kikuchi, Y., \& Senoo, A. (2008). The functional neuroanatomy of maternal love: Mother's response to infant's attachment behaviors. Biological Psychiatry, 63(4), 415-423. doi:10.1016/j.biopsych.2007.05.018

Otto, R. (1946). The idea of the holy: An inquiry into the nonrational factor in the idea of the divine and its relation to the rational (rev ed.). London, UK: Oxford University Press.

Panda, R., Bharath, R. D., Upadhyay, N., Mangalore, S., Chennu, S., \& Rao, S. L. (2016). Temporal dynamics of the default mode network characterize meditation-induced alterations in consciousness. Frontiers in Human Neuroscience, 10, 372. doi:10.3389/fnhum.2016.00372

Piedmont, R. L. (1999). Does spirituality represent the sixth factor of personality? Spiritual transcendence and the five-factor model. Journal of Personality, 67(6), 985-1013. doi:10.1111/ 1467-6494.00080

Potenza, M. N., Balodis, I. M., Derevensky, J., Grant, J. E., Petry, N. M., Verdejo-Garcia, A., \& Yip, S. W. (2019). Gambling disorder. Nature Reviews Disease Primers, 5(1), 51. doi:10.1038/s41572-019-0099-7

Potenza, M. N., Hong, K. I., Lacadie, C. M., Fulbright, R. K., Tuit, K. L., \& Sinha, R. (2012). Neural correlates of stress-induced and cue-induced drug craving: Influences of sex and cocaine dependence. The American Journal of Psychiatry, 169(4), 406-414. doi:10.1176/appi.ajp.2011.11020289

Potenza, M. N., Steinberg, M. A., Skudlarski, P., Fulbright, R. K., Lacadie, C. M., Wilber, M. K., Rounsaville, B. J., Gore, J. C., \& Wexler, B. E. (2003). Gambling urges in pathological gambling: A functional magnetic resonance imaging study. Archives of General Psychiatry, 60(8), 828-836. doi:10.1001/ archpsyc.60.8.828

Rodd, J. M., Longe, O. A., Randall, B., \& Tyler, L. K. (2010). The functional organisation of the fronto-temporal language system: Evidence from syntactic and semantic ambiguity. Neuropsychologia, 48(5), 1324-1335. doi:10.1016/j.neuropsychologia. 2009.12.035

Saver, J. L., \& Rabin, J. (1997). The neural substrates of religious experience. In S. Salloway, P. Malloy, \& J. L. Cummings (Eds.), The neuropsychiatry of limbic and subcortical disorders (pp. 195-207). Washington, DC: American Psychiatric Press.

Serences, J. T., Shomstein, S., Leber, A. B., Golay, X., Egeth, H. E., \& Yantis, S. (2005). Coordination of voluntary and stimulus-driven attentional control in human cortex. Psychological Science, 16(2), 114-122. doi:10.1111/j.0956-7976. 2005.00791.x

Shonin, E., Van Gordon, W., \& Griffiths, M. (2014). Mindfulness as a treatment for behavioural addiction. Journal of Addiction Research \& Therapy, 5(1), e122. doi:10.4172/2155-6105. $1000 \mathrm{e} 122$

Simons, J. S., \& Spiers, H. J. (2003). Prefrontal and medial temporal lobe interactions in long-term memory. Nature Reviews Neuroscience, 4(8), 637-648. doi:10.1038/nrn1178

Sinha, R. (2008). Chronic stress, drug use, and vulnerability to addiction. Annals of the New York Academy of Sciences, 1141(1), 105-130. doi:10.1196/annals.1441.030

Skarupski, K. A., Fitchett, G., Evans, D. A., \& Mendes de Leon, C. F. (2010). Daily spiritual experiences in a biracial, community-based population of older adults. Aging \& Mental Health, 14(7), 779-789. doi:10.1080/13607861003713265

Sporns, O. (2013). Structure and function of complex brain networks. Dialogues in Clinical Neuroscience, 15(3), 247. Retrieved from https://www.dialogues-cns.org/

Tang, Y. Y., Holzel, B. K., \& Posner, M. I. (2015). The neuroscience of mindfulness meditation. Nature Reviews Neuroscience, 16(4), 213-225. doi:10.1038/nrn3916

Tang, Y.-Y., Ma, Y., Fan, Y., Feng, H., Wang, J., Feng, S., Lu, Q., Hu, B., Lin, Y., Li, J., Zhang, Y., Wang, Y., Zhou, L., \& Fan, M. (2009). Central and autonomic nervous system interaction is altered by short-term meditation. Proceedings of the National Academy of Sciences of the United States of America, 106(22), 8865-8870. doi:10.1073/pnas.0904031106

Tang, Y. Y., Tang, R., \& Posner, M. I. (2016). Mindfulness meditation improves emotion regulation and reduces drug abuse. Drug and Alcohol Dependence, 163(Suppl. 1), S13-S18. doi:10.1016/j.drugalcdep.2015.11.041 
Uddin, L. Q., Molnar-Szakacs, I., Zaidel, E., \& Iacoboni, M. (2006). rTMS to the right inferior parietal lobule disrupts self-other discrimination. Social Cognitive and Affective Neuroscience, 1(1), 65-71. doi:10.1093/scan/ns1003

Underhill, E. (1911). Mysticism: A study in the nature and development of man's spiritual consciousness. London: Methuen.

Urgesi, C., Aglioti, S. M., Skrap, M., \& Fabbro, F. (2010). The spiritual brain: Selective cortical lesions modulate human selftranscendence. Neuron, 65(3), 309-319. doi:10.1016/j.neuron. 2010.01 .026

Vago, D. R., \& Zeidan, F. (2016). The brain on silent: Mind wandering, mindful awareness, and states of mental tranquility. Annals of the New York Academy of Sciences, 1373(1), 96-113. doi:10.1111/nyas.13171

Vaillant, G. E. (2008). Spiritual evolution: How we are wired for faith, hope, and love. New York, NY: Broadway Books.

Van Veen, V., \& Carter, C. S. (2002). The anterior cingulate as a conflict monitor: fMRI and ERP studies. Physiology \& Behavior, 77(4-5), 477-482. doi:10.1016/s0031-9384(02)00930-7

Vanderwal, T., Hunyadi, E., Grupe, D. W., Connors, C. M., \& Schultz, R. T. (2008). Self, mother and abstract other: An fMRI study of reflective social processing. Neuroimage, 41(4), 1437-1446. doi:10.1016/j.neuroimage.2008.03.058

Vogeley, K., \& Fink, G. R. (2003). Neural correlates of the firstperson-perspective. Trends in Cognitive Sciences, 7(1), 38-42. doi:10.1016/S1364-6613(02)00003-7

Vossel, S., Geng, J. J., \& Fink, G. R. (2014). Dorsal and ventral attention systems: Distinct neural circuits but collaborative roles. Neuroscientist, 20(2), 150-159. doi:10.1177/10738584 13494269

Vossel, S., Weidner, R., Thiel, C. M., \& Fink, G. R. (2009). What is "odd" in Posner's location-cueing paradigm? Neural responses to unexpected location and feature changes compared. Journal of Cognitive Neuroscience, 21(1), 30-41. doi:10.1162/jocn.2009.21003

Waldron, J. L. (1998). The life impact of transcendent experiences with a pronounced quality of noesis. The Journal of Transpersonal Psychology, 30(2), 103. Retrieved from atpweb.org/ jtparchive/trps-30-98-02-103.pdf

Wang, A. T., Lee, S. S., Sigman, M., \& Dapretto, M. (2007). Reading affect in the face and voice: Neural correlates of interpreting communicative intent in children and adolescents with autism spectrum disorders. Archives of general psychiatry, 64(6), 698-708. doi:10.1001/archpsyc.64.6.698

Wexler, B. E., Gottschalk, C. H., Fulbright, R. K., Prohovnik, I., Lacadie, C. M., Rounsaville, B. J., \& Gore, J. C. (2001). Functional magnetic resonance imaging of cocaine craving. American Journal of Psychiatry, 158(1), 86-95. doi:10.1176/ appi.ajp.158.1.86

Whitehead, B. R., \& Bergeman, C. S. (2011). Coping with daily stress: Differential role of spiritual experience on daily positive and negative affect. Journals of Gerontology Series B: Psychological Sciences and Social Sciences, 67(4), 456-459. doi:10.1093/geronb/gbr136

Witkiewitz, K., Bowen, S., Harrop, E. N., Douglas, H., Enkema, M., \& Sedgwick, C. (2014). Mindfulness-based treatment to prevent addictive behavior relapse: Theoretical models and hypothesized mechanisms of change. Substance Use \& Misuse, 49(5), 513-524. doi:10.3109/10826084.2014.891845

Worhunsky, P. D., Dager, A. D., Meda, S. A., Khadka, S., Stevens, M. C., Austad, C. S., Raskin, S. A., Tennen, H., Wood, R. M.,
Fallahi, C. R., Potenza, M. N., \& Pearlson, G. D. (2016). A preliminary prospective study of an escalation in 'Maximum Daily Drinks', fronto-parietal circuitry and impulsivity-related domains in young adult drinkers. Neuropsychopharmacology, 41(6), 1637-1647. doi:10.1038/npp.2015.332

Worhunsky, P. D., Potenza, M. N., \& Rogers, R. D. (2017). Alterations in functional brain networks associated with loss-chasing in gambling disorder and cocaine-use disorder. Drug and Alcohol Dependence, 178, 363-371. doi:10.1016/ j.drugalcdep.2017.05.025

Worhunsky, P. D., Stevens, M. C., Carroll, K. M., Rounsaville, B. J., Calhoun, V. D., Pearlson, G. D., \& Potenza, M. N. (2013). Functional brain networks associated with cognitive control, cocaine dependence, and treatment outcome. Psychology of Addictive Behaviors, 27(2), 477-488. doi:10.1037/ a0029092

Xu, J., Calhoun, V. D., Pearlson, G. D., \& Potenza, M. N. (2014). Opposite modulation of brain functional networks implicated at low vs. high demand of attention and working memory. PLoS One, 9(1), e87078. doi:10.1371/journal.pone.0087078

$\mathrm{Xu}$, J., Calhoun, V. D., \& Potenza, M. N. (2015). The absence of task-related increases in BOLD signal does not equate to absence of task-related brain activation. Journal of Neuroscience Methods, 240, 125-127. doi:10.1016/j.jneumeth.2014. 11.002

Xu, J., Calhoun, V. D., Worhunsky, P. D., Xiang, H., Li, J., Wall, J. T., Pearlson, G. D., \& Potenza, M. N. (2015). Functional network overlap as revealed by fMRI using sICA and its potential relationships with functional heterogeneity, balanced excitation and inhibition, and sparseness of neuron activity. PLoS One, 10(2), e0117029. doi:10.1371/journal.pone.0117029

Xu, J., Potenza, M. N., \& Calhoun, V. D. (2013). Spatial ICA reveals functional activity hidden from traditional fMRI GLMbased analyses. Frontiers in Neuroscience, 7, 154. doi:10. 3389/fnins.2013.00154

Xu, J., Potenza, M. N., Calhoun, V. D., Zhang, R., Yip, S. W., Wall, J. T., Pearlson, G. D., Worhunsky, P. D., Garrison, K. A., \& Moran, J. M. (2016). Large-scale functional network overlap is a general property of brain functional organization: Reconciling inconsistent fMRI findings from general-linear-modelbased analyses. Neuroscience and Biobehavioral Reviews, 71, 83-100. doi:10.1016/j.neubiorev.2016.08.035

Xu, J., Zhang, S., Calhoun, V. D., Monterosso, J., Li, C.-S. R., Worhunsky, P. D., Stevens, M., Pearlson, G. D., \& Potenza, M. N. (2013). Task-related concurrent but opposite modulations of overlapping functional networks as revealed by spatial ICA. Neuroimage, 79, 62-71. doi:10.1016/j.neuroimage.2013.04.038

Yaden, D. B., Haidt, J., Hood, R. W., Jr., Vago, D. R., \& Newberg, A. B. (2017). The varieties of self-transcendent experience. Review of General Psychology. Advance online publication. doi:10.1037/gpr0000102

Yao, Y., Liu, L., Ma, S. S., Shi, X. H., Zhou, N., Zhang, J. T., \& Potenza, M. N. (2017). Functional and structural brain alterations in Internet gaming disorder: A systematic review and meta-analysis. Neuroscience and Biobehavioral Reviews, 83, 313-324. doi:10.1016/j.neubiorev.2017.10.029

Yin, H. H., \& Knowlton, B. J. (2006). The role of the basal ganglia in habit formation. Nature Reviews Neuroscience, 7(6), 464-476. doi:10.1038/nrn1919

Zhang, J.-T., Yao, Y.-W., Potenza, M. N., Xia, C.-C., Lan, J., Liu, L., Wang, L. J., Liu, B., Ma, S. S., \& Fang, X.-Y. (2016). 
Effects of craving behavioral intervention on neural substrates of cue-induced craving in Internet gaming disorder. NeuroImage: Clinical, 12, 591-599. doi:10.1016/j.nicl.2016. 09.004

Zhang, J.-T., Yao, Y.-W., Potenza, M. N., Xia, C.-C., Lan, J., Wang, L-J, Liu, B., Ma, S. S., \& Fang, X.-Y. (2016). Altered resting-state neural activity and changes following a craving behavioral intervention for Internet gaming disorder. Scientific Reports, 6(1), 28109. doi:10.1038/srep28109

Zhang, S., Tsai, S. J., Hu, S., Xu, J., Chao, H. H., Calhoun, V. D., \& Li, C. S. R. (2015). Independent component analysis of functional networks for response inhibition: Inter-subject variation in stop signal reaction time. Human Brain Mapping, 36(9), 3289-3302. doi:10.1002/hbm.22819 